\title{
Afyonkarahisar Yorganlarının Teknik, Desen ve Kompozisyon Özellikleri
}

\section{Technical, Pattern and Composition Specifications of Afyonkarahisar Quilts}

\author{
Arş. Gör. Dr. Ülkü KÜÇÜKKURT ${ }^{\text {iD } 1}$
}

\begin{abstract}
$\ddot{O} \mathbf{z}$
İnsanlık tarihi kadar eski olan temel ihtiyaçlar içinde örtünme yer almaktadır. Teknik ve estetik anlamda kendini geliştiren insan, yorgan üretiminde bu süreci yaşamıştır. Dîvânu Lugâti't Türk'te yorgan: Yogurkan, yörgen olarak geçmektedir. Türklerin tarihinde yorgan her dönem önemini korumuş, hayatın vazgeçilmez bir parçası olmuştur. Ege bölgesinde yer alan ve karasal iklime sahip Afyonkarahisar'da günlük kullanılan eşyalar ve çeyiz geleneğinde yorganın önemli bir yeri vardır. Şer'iye sicillerinde yorganlar, kayıt altına alınmıştır. Afyonkarahisar'da yorgan dikimi atölyelerde ve evlerde yapılmakta, atölyelerde erkekler, evlerde kadın ustalar çalışmaktadır. Afyonkarahisar'da yün, pamuk dolgulu yorganlar dikilmektedir. Yorganlarda açık renkler, pastel tonlar tercih edilmektedir. Motifler bitkilerden, eşyalardan ve geometrik şekillerden oluşturulmuştur. Hazır yorganların mağazalarda yerini almasıyla el dikimi yorganlara ilgi azalmış, zamanla arz ve talebe bağlı olarak yorgan ustalarının sayısında azalma meydana gelmiştir. Çalışmada, alan araştırması yöntemi kullanılarak kaybolmaya yüz tutmuş Afyonkarahisar el dikimi yorganlarının, incelenerek yazılı kaynak haline getirilmesi amaçlanmıştır. Araştırmada, yorganların Afyonkarahisar kültüründe ki yerine, üretiminde kullanılan malzemelere, dikim tekniklerine, desen özellikleri ile yorgan örneklerine yer verilmiş, üretimin devamına yönelik önerilerde bulunulmuştur.
\end{abstract}

Anahtar Kelimeler: Afyonkarahisar, kültür, yorgan, yorgan üretimi, yorgan motifleri

Makale Türü: Araştırma

\begin{abstract}
Covering their bodies is one of the basic needs of humankind, which is as old as the history of humanity. Humans who developed themselves in technical and aesthetic sense experienced this process in the production of quilts. The quilt in Diwan-1 Lughat Al Turk is referred to as yogurkan or yörgen. In the history of Turks, quilts have always been important and have been an indispensable part of life. At Afyonkarahisar in the Aegean region, which has a continental climate, quilts have an important place within the daily items and dowery tradition. Quilts were recorded in the Şeriye registers In Afyonkarahisar, quilt production is done in workshops and houses, men work in workshops, and female crafters work in houses. Wool and cotton-filled quilts are sewn in Afyonkarahisar. Light colors and pastel tones are preferred in quilts. Motives represent plants, objects and geometric shapes. With the availability of ready-made quilts in stores, interest in hand sewing quilts decreased, and the number of quilt masters decreased in time due to supply and demand. In this study, it is aimed to transform the quilts of Afyonkarahisar, which are among the traditional arts and in the brink of being lost, by using the field research method. In the research, place of the quilt in Afyonkarahisar culture, the materials used in production, sewing techniques, pattern characteristics quilt samples were mentioned and suggestions were made for the continuation of this art.
\end{abstract}

Keywords: Afyonkarahisar, culture, quilt, quilt production, quilt motifs

Paper Type: Research

\footnotetext{
${ }^{1}$ Afyon Kocatepe Üniversitesi, Güzel Sanatlar Fakültesi, ukkurt@aku.edu.tr.

Atıf için (to cite): Küçükkurt, Ü. (2019). Afyonkarahisar Yorganlarının Teknik, Desen ve Kompozisyon Özellikleri, Afyon Kocatepe Üniversitesi Sosyal Bilimler Dergisi, 21(3), 1014-1027.
} 


\section{Giriş}

İnsanlık tarihi kadar eski olan temel ihtiyaçlar içinde uyuma esnasında kişinin örtünmesi yer almaktadır. İlk insanlar önceleri bitkileri, daha sonra hayvan yetiştiriciliğinin gelişmesiyle yün malzemeden oluşturulmuş keçe ve dokumaları yorgan olarak kullanmıştır. Yapılan bilimsel araştırmalar uyku kalitesinin önemli olduğunu göstermektedir. Bu nedenle uyku esnasında üşüme hissini gidermek için kullanılan yorganların üretim malzemelerinin sağlıklı olması gerekmektedir. Yorganların üretiminde kullanılan malzemeler ve dikiş teknikleri zamanla gelişme göstermiş, ürünlerin görselliğine verilen önem artmıştır.

Birçok kültürde olduğu gibi Türklerin kullandığı eşyalar arasında yorganın yeri ayrıdır. Türk kültüründe yorgan örtünmek, bürünmek için kullanılan bir söz olarak ortaya çıkmıştır. Çobanların, geceleri bürünerek yattıkları büyük bir aba da yorgan olarak adlandırılıyordu. Eski Türklerde "Yorgan" karı-kocalık sembolüdür. Dede korkut kitabında yer alan bir söyleşmede yer almaktadır; "Ala yorgan içinde senin ile dolaşmadım, tatlı damag tutıbanı soruşmadım, al duvağım altından söyleşmedim” (Ögel, 1991: 221, 224).

Dîvânu Lugâti’t Türk’te yorgan: Yogurkan, bürünmek örtünmek, yörgen olarak geçmektedir. "Anın üze yogurkan eşildi-onun üzerine örtü örtüldü”, "Uragut yogurkan büründikadın yorgana büründü ve yüzünü kapadı", "Yogurkan-yorgan”, " Ol anar yogurkan eşüdi- O, ona yorgan örttü", "Er yogurkanka yörgendi-adam yorgana sarındı" (Ercilasun ve Akkoyunlu, 2015: 97, 273, 371, 458, 391). XI. yüzyılda Türk evlerinin konfor vasıtalarının içinde minder, yastık, duvar halıları, yatak, yorgan bulunmaktadır. Yatak, yorgan ve yastığın birinci planda geceleri yatıp uyumak amacıyla kullanılmış olduğu muhakkaktır. Fakat bu eşyalar aynı zamanda döşemelik kullanılmıştır (Genç, 1997: 214). Yorgan, yastık gibi eşya üretip satan kişiler "Yorgancı" olarak tanımlanmaktadır (Duman, 2007: 68).

Türk Uygarlık tarihinde yorgan her zaman önemini korumuştur. Osmanlı İmparatorluğu'nda halk ve saray yorgan üretiminde en kıymetli kumaşları kullanmış, yorganlar çeyiz adetlerinde yer almıştır. Bu döneme ait Topkapı Sarayı Müzesi'nde bulunan iki çocuk yorganı örnektir. Bu yorganlar 18. yüzyılda, telli ve çiçekli kumaştan yapılmıştır (Öz, 1951: 68). (Şekil 1).

Şekil 1. Topkapı Sarayı Müzesi'nde 5832 numaralı çocuk yorganı. Beyaz telli zemin üzerine kahverengi yapraklar ve sarı karanfillerle süslenmiştir.

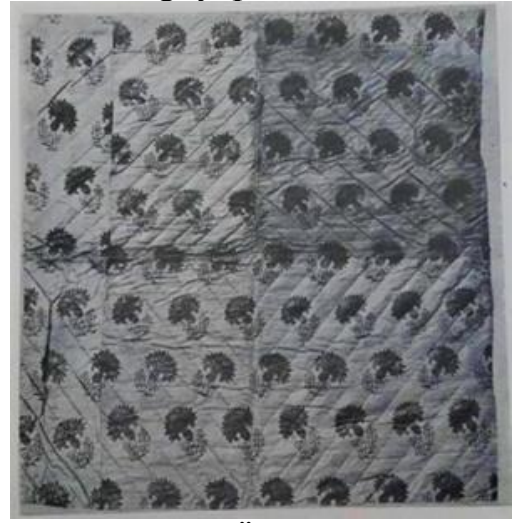

Kaynak: Öz, 1951: 73

Anadolu'nun birçok bölgesinde seçkin yorgan örneklerine rastlamak mümkündür. $\mathrm{Bu}$ yerlerden birisi de Afyonkarahisar'dır. Afyonkarahisar' da yorgan üretimi bir meslek olmasının yanında üzerinde taşıdığı desenlerle yöre insanının zevkini yansıtan bir kültür unsurudur. Makineleşme, insanların değişen yaşam tarzı birçok iş kolunu etkilediği gibi yorgan üretimini etkilemiş, usta sayısında düşüş meydana gelmiş, yorgan desenlerinin gün geçtikçe unutulmasına yol açmıştır. Bu nedenle araştırma başlığı "Afyonkarahisar Yorganlarının Teknik, Desen ve 
Kompozisyon Özellikleri” olarak belirlenmiștir. Afyonkarahisar kültüründe yorganın yeri, üretiminde kullanılan araçlar, gereçler, teknikler, desenler, kompozisyonlar ve günümüzdeki üretim durumuna yer verilerek kayıt altına alınması, bu konuda araştırma yapacaklara 1şık tutması amaçlanmıştır.

\section{Materyal ve Yöntem}

Araştırma, Afyonkarahisar yorganlarının teknik, desen ve kompozisyon özellikleri olarak sınırlandırılmıştır. Yörede elde dikilmiş, geleneksel desenleri taşıyan yorganlar incelenmiş, 27 adet farklı desene sahip yorgan örneğine ulaşılmıştır. $\mathrm{Bu}$ örnekler fotoğraflanmış, ebatları, malzeme, teknik ve desen özellikleri tespit edilmiştir. Araştırmada 13 adet örneğin görseline yer verilmiştir.

Araştırmada alan araştırması yöntemine ek olarak konu ile ilgili kaynak taraması yapılmıştır. Kaynaklardan elde edilen bilgilerle, alan araştırmasında elde edilen bilgiler değerlendirilmiştir.

Araştırmanın sonuç bölümünde, Afyonkarahisar yorganlarının günümüzdeki durumuna değinilerek, yorgan üretiminin sürdürülebilmesi, desenlerinin korunabilmesi için önerilerde bulunulmuştur.

\section{Bulgular}

\subsection{Afyonkarahisar Kültüründe Yorgan}

Ege bölgesinin iç kısmında yer alan karasal iklime sahip Afyonkarahisar'da, günlük kullanılan eşyalar ve çeyiz geleneğinde yorgan bulunmaktadır. Yorgan olmadan yeni bir evin açılması mümkün görülmemiştir. Yorganlar, şer'iyye sicillerinde, miras kayıtlarında yer almıştır. Evlenme, doğum, sünnet adetlerinde yorgan çeyizin içindedir. Evlenme adetlerinde, gelin kendi çeyizi için desenli, saten yüzlü yorgan diktirmektedir. Ayrıca gelinin ailesinin maddi durumu iyi ise kayınvalidesine yorgan ve yatak takımları hediye etmektedir. Doğum ve sünnet adetlerinde kız annesi çeyizin büyük bölümünü üstlenmektedir. Yatak, yatak takımları, saten yüzlü desenli yorganlar, giyecekler ailenin maddi durumuna göre hazırlanmaktadır. Lohusanın ve bebeğin yattığı yataklar süslenmekte, yorganlara işlemeli yorgan ağızlı̆̆ geçirilmektedir (Şekil 2, 3). Ayrıca salıncak ve beşik için çok küçük boyutta süslü bebek yorganları diktirilmektedir (Yalçınkaya, sözlü görüşme, 2019). Sünnet çocuğunun yatağına ayrı özen gösterilmekte, yatak takımları ve yorgan yüzleri kıymetli kumaşlardan seçilmektedir.

Şekil 2. R. Gülenay Yalçınkaya’nın, Güneş İlker Yalçınkaya’yı dünyaya getirdiğinde hazırlanan lohusa yatağı, Afyonkarahisar.

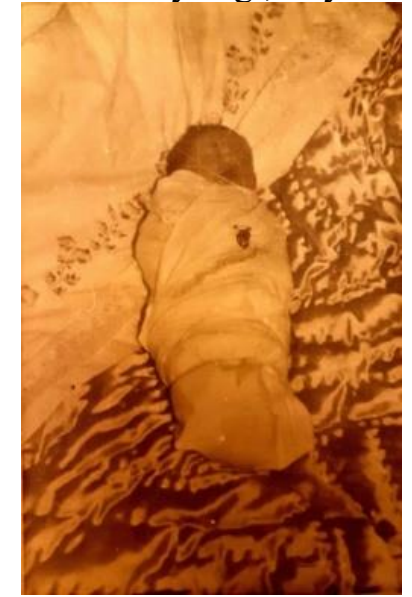

Kaynak: Yalçınkaya, 1981 
Şekil 3. Çeyiz için hazırlanmış, ağzı dikilmiş saten desenli yorganlar, Afyonkarahisar Belediyesi Kültür Sanat Evi.

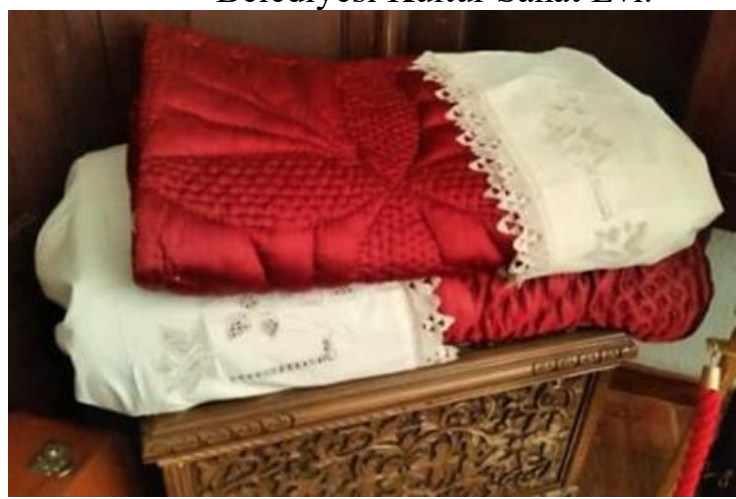

Kaynak: Küçükkurt, 2019

Afyonkarahisar'da yorgan dikimi atölyelerde ve evlerde yapılmıştır. Atölyelerde erkekler, evlerde kadın ustalar çalışmıştır. Hazır yorganların mağazalarda yerini almasıyla el dikimi yorganlara ilgi azalmış, zamanla arz ve talebe bağlı olarak yorgan ustalarının sayısında düşüş meydana gelmiştir. Günümüzde Afyonkarahisar Esnaf ve Sanatkârlar Odası Birliği'ne 3 yorgan üreticisi kayıtlıdır (Uzun, sözlü görüşme, 2018). Odaya kayıtlı 2 yorgan üreticisi, yorgan malzemesi ya da makinede dikilmiş hazır yorganları dükkânlarında satmakta sadece ticaret yapmaktadır. Kayıtlı üreticilerden 3. olan İsmet Kartal atölyesinde elle yorgan dikimini gerçekleştirmekte evlerde ise yorgan dikimini kadınlar sürdürmektedir.

1944 yılında Afyonkarahisar'da dünyaya gelen İsmet Kartal, geleneksel yöntemle ve çeşitli desenler kullanarak yorgan üretmektedir. Babası Hüseyin Kartal (1888-1968) keçecilik mesleği ile meşgul iken annesi Huriye Kartal (1930-2010) evde yorgan dikerek aile ekonomisine destek olmuştur. Ortaokul mezunu olan İsmet Kartal Usta, yorgan dikmeyi annesinden öğrenmiştir. Huriye Kartal belirli yorgan desenlerini uyguluyordu. İsmet Kartal, Yorgan Ustası Cemil Çetinbaş'ın yanında çalışmaya başladığında yorgan modelleri konusunda kendini geliştirmiştir. Cemil Usta'nın dükkânı Bedesten yakınında Kadınlar Pazarı'nda bulunmaktaydı. Günümüzde bu atölye faaliyette değildir. Annesinden öğrendiği baklava şişesi, göbekli, çavuş sırması modellerine ek ustasından pervane, parke, menekşe, paket taşı, ikili, üçlü parke taş1, şemsiye, serpme lale modellerini öğrenmiştir (Kartal, sözlü görüşme, 2019). (Şekil $4,5)$.

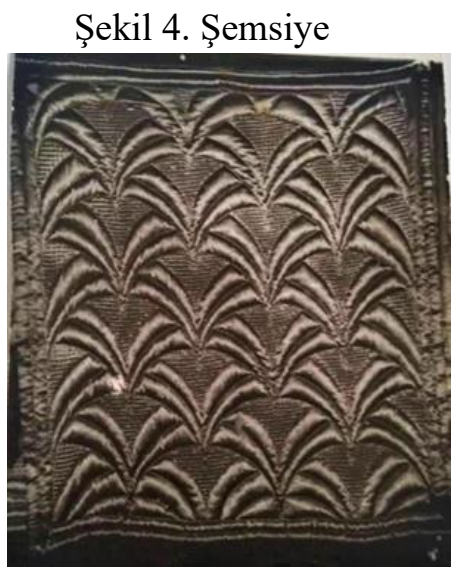

Kaynak: Kartal, 1990
Sekil 5. Serpme lale

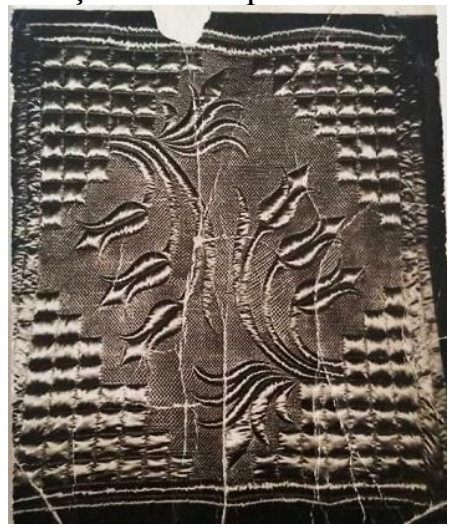

Kaynak: Kartal, 1990

İsmet Kartal, ideal yorganı şu şekilde tarif etmektedir; "Sağlıklı yorgan kullanılmazsa vücut çile çeker. Sağlıklı yorgandan kastım iç malzemesinin doğal olmasıdır. Yorgan çok kalın olmamalıdır. Kalın yorgan insanı 1sıtmaz. Sanki insanı, makine halısının altına girmiş gibi 
hissettirir. İyi yorgan insanın üstüne düşmelidir. Yorgan, uygun incelikte olursa ortopedik özelliklere sahip olur. $\mathrm{Bu}$ nedenle dikiş sıklığına dikkat edilmelidir. Sık dikiş yorganı sertleştirmektedir. Ayrıca seçilecek kumaşın uygun incelikte olması gerekmektedir. İki kat kumaş, iç malzemesi ve dikiş eklenince yorgan kalınlaşmaktadır. İyi usta bu konuları dikkate almaktadır" (Kartal, sözlü görüşme, 2019).

\subsection{Afyonkarahisar'da Geleneksel Yorgan Üretimi}

\subsubsection{Yorgan Üretiminde Kullanılan Araçlar ve Gereçler}

Yorgan üretiminde kullanılan araçlar içinde hallaç makinesi, dikiş makinesi, terazi, cetvel, mezura, makas, iğne, dikiş yüzüğü, tebeşir, kurşun kalem, pergel, desen kalıpları, balmumu, sirık yer almaktadır. makinedir.

Hallaç makinesi; yün ve pamuğun taranması, kabartılması işleminde kullanılan bir

Dikiş makinesi; yorganın "Torba" denilen dış kabının hazırlanmasında kullanılmaktadır.

Terazi; iç malzemenin ağırlığının ölçülmesinde, cetvel ve mezura; kumaşın uzunluğunun belirlenmesinde, makas; kumaşın biçilmesinde, çeşitli boylarda çelik yorgan iğneleri; dikme işleminde, dikiş yüzüğü; iğnenin baskısından parmağı korumak için kullanılmaktadır. Balmumu; ipliğin yorgan iğnesine kolay takılmasını, sağlamlaşmasını ve çabuk kopmamasını sağlamaktadır. Desenin yorgan yüzüne çizilmesinde tebeşir, sabun, kurşun kalem ve pamuk ipliği tercih edilmektedir. Tebeşire sürülen pamuk ipliği gerginleştirilip bırakılmakta böylece kumaş yüzeyinde düzgün çizgiler elde edilmektedir. Pergel; kalıp oluşturulmasında, yüzeye desenin düzgün geçirilmesinde, sırık; yorgan iç malzemesinin alana düzgün yayılmasında kullanılmaktadır.

Desen kalıpları; yorgana uygulanacak desenin kumaşa düzgün çizilmesi için hazırlanan mukavva kalıplardır. Birçok desen ustaların hafizasında olmasına rağmen bazı desenlerde kalıp kullanılmaktadır. Bu kalıplar, bir birini tamamlayan ya da kendini tekrar eden desenler şeklinde hazırlanmaktadır (Şekil 6).

Şekil 6. Desen kalıpları, İsmet Kartal Atölyesi, Afyonkarahisar.

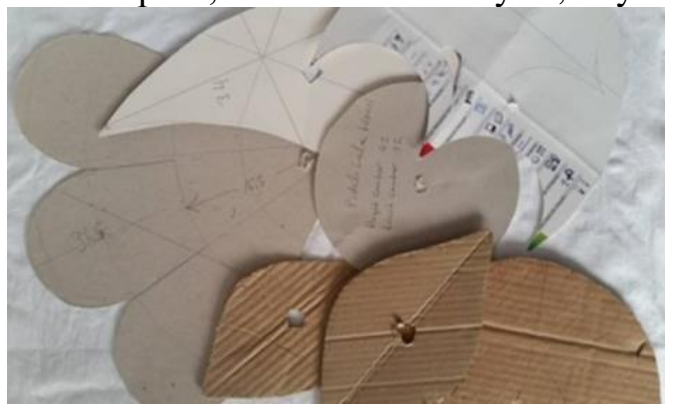

Kaynak: Küçükkurt, 2019

Yorgan dikiminde kullanılan gereçler arasında iplik, dolgu malzemeleri ve çeşitli kumaşlar yer almaktadır.

İplik; pamuk, ipek ve naylon iplikler yorgan dikiminde deseni oluşturmak, dolgu malzemesini sabitlemek için kullanılmaktadır. Naylon iplikler daha dayanıklı olduğu için ustalar tarafından tercih edilmektedir.

Dolgu malzemesi; koyun yünü, kuzu yünü, pamuk, yün ve pamuk karışımı malzemeler yorganlarda kullanılmaktadır (Şekil 7). Boncuk elyaf dolgulu yorganı diktirmek isteyen alıcı çok azdır. Ayrıca yorgan ustaları boncuk elyafını, iç malzemesi olarak kullanmayı istememektedir. Boncuk elyafı dikim esnasında sürekli kaymakta sabitlenmesi zor olmaktadır (Kartal, sözlü görüşme, 2019). 
Şekil 7. Solda harman hallaç makinesinde taranacak yün, sağda atımdan gelmiş doldurulmaya hazır pamuk, Afyonkarahisar.
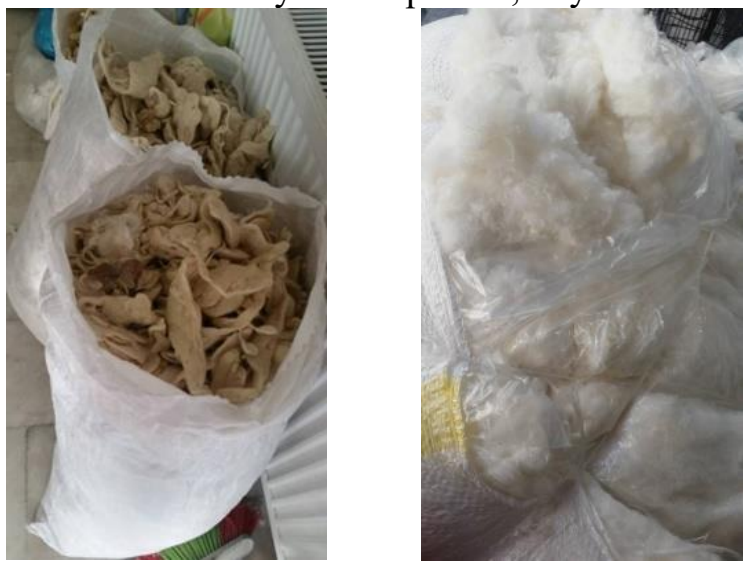

Kaynak: Küçükkurt, 2018

Yün dolgulu yorganlar kış, pamuk dolgulu yorganlar yaz için tercih edilmektedir. Alıcının isteğine bağlı olarak sadece yün malzeme kullanıldığı gibi belirli oranlarda yün ve pamuk karıştırılmış dolgulu yorganlar dikilmektedir. Yün-pamuk karışımlı dolgulu yorganların dikimi daha kolay olmaktadır. İğne, deseni oluşturmak için dolguya daldırıldığında malzemeyi tutmakta, malzeme daha rahat oturarak deseni ortaya çıkartmaktadır. Yün, pamuğa göre ipi gevşek tutmaktadır. Pamuk dokusundan dolayı ipliğin kolay kaymasını engellemektedir. Böylece ipliğe düşen baskı azalmakta ve sökülme olasılığ 1 düşmektedir. Ayrıca yorgan daha kabarık "Puf, puf” durmaktadır (Kartal, sözlü görüşme, 2019).

Yorgan dikiminde kullanılan kumaşlar; ustalar, yorgan dikiminde seçtikleri kumaşların ince olmasına dikkat etmektedir. Bunun sebebi, iç dolgu malzemesi ve kumaşın ağırlığının birleşip yorganı daha da ağırlaştırmasıdır. Bu etkenlere ilave olarak yorganın yumuşak olması, dikişinin iyi oturması ve desenin daha kabarık durmasını sağlamaktadır.

Yorganın alt kısmında kullanılan kumaşa "Astar", üst kısmında kullanılan kumaşa "Yüzlük" denilmektedir (Şekil 8). Eskiden Afyonkarahisar' da dikilen yorganların astarında halk arasında "Tülbentlik Bez" denilen "Mermerşahi" kullanılmıştır. Mermerşahi beyazlatılmış, yumuşak tuşeli bir kumaştır (Yardımcı, 2008: 27). Günümüzde bu kumaşların yerini "Patiska" gibi biraz daha kalın kumaşlar almıştır. Günlük kullanım için dikilen ve tamamen nevresime girecek yorganlarda saten gibi pahalı kumaşlar kullanılmamakta astarı ve yüzü için patiska kullanılmaktadır. Bunun bir diğer nedeni de patiska kumaşın nevresimi tutmasıdır. Aksi halde yorgan nevresimin içinde kaymakta düzgün durmamaktadır (Darı, sözlü görüşme, 2019).

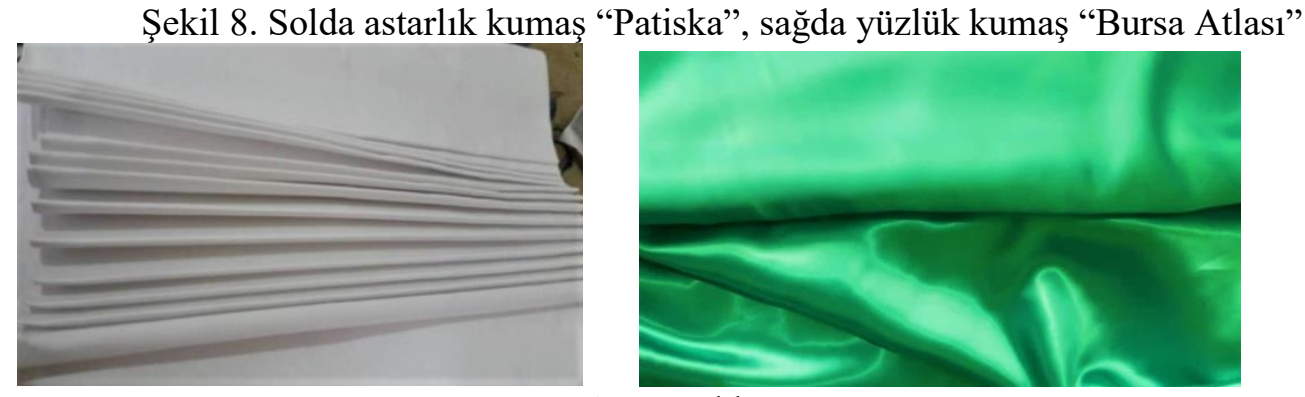

Kaynak: Küçükkurt, 2019

Yorganların yüzünde eskiden "Bursa Atlası", İşlemeli Saten" ve "Basma" kumaşlar kullanılmıştır (Şekil 9, 10). Günümüzde, dokusundan ve üzerindeki kabartma deseninden dolayı "Deri Saten" denilen kumaşların yanı sıra, "İpek Denim" kumaşlar yorganların yüzünde 
kullanılmaktadır (Kartal, sözlü görüşme, 2019). Deri saten tamamen sentetik, parlak, kendinden desenli ya da desensiz bir kumaştır. Basma kumaşlar, bezayağı tekniğinde pamuk iplikle dokunmuş kumaşlara desen, baskı yoluyla uygulanmaktadır (Çeliker ve Ölmez, 2012: 128).

Şekil 9. Ön yüzü basma kumaş, astarı mermerşahi kumaştan dikilmiş yorgan

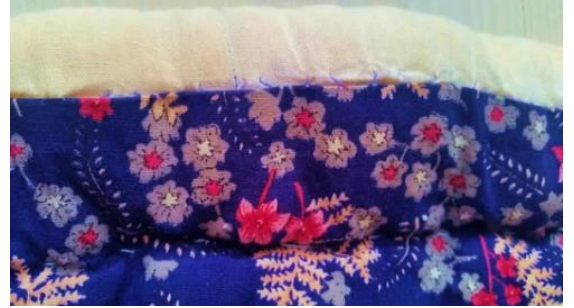

Kaynak: Küçükkurt, 2019

Şekil 10. Solda Halk arasında "İşlemeli Saten” denilen kumaş, sağda "Deri Saten”, İsmet Kartal Yorgan Atölyesi, Afyonkarahisar.
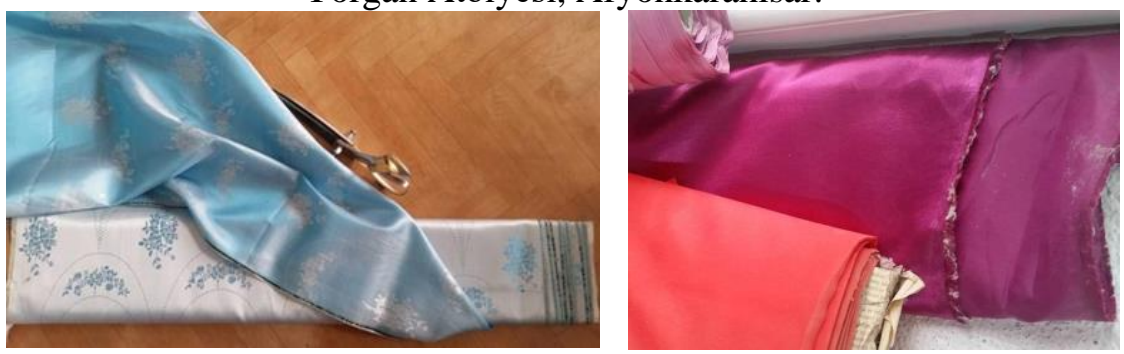

Kaynak: Küçükkurt, 2019

\subsubsection{Yorganların Dikimi}

Yorganların dikim işlemine başlamadan önce hangi amaç ve boyutlarda dikileceğine karar verilmektedir. Yorganları dikim amacina göre;

1. Günlük kullanım için dikilen yorganlar,

2. Çeyiz için dikilen yorganlar (Gelin çeyizi, anne çeyizi, bebek çeyizi, sünnet çeyizi) olarak gruplandırabiliriz.

Günlük kullanım için dikilen yorganların astarında ve yüzünde patiska kumaş kullanılmaktadır. Bu yorganlar nevresimin içine geçirilmektedir. Çeyizlik yorganlarda deri saten ve diğer parlak görünümlü kumaşlar kullanılmakta, bu yorganların parlak ve desenli kısmını kapatmayacak şekilde düğmeli nevresim geçirilmektedir (Şekil 11).

Şekil 11. Baklava şişesi desenli, ön yüzü "Deri Saten”, arka yüzü "Patiska” kumaş yorgan, İsmet Kartal Atölyesi, Afyonkarahisar.

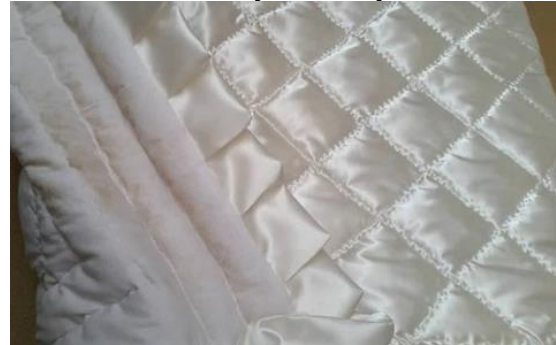

Kaynak: Küçükkurt, 2019

Yorganın kullanım amacı belirlendikten sonra ebadı tespit edilmektedir. Yorganlar:

1. Tek kişilik; $155 \mathrm{~cm} \times 215 \mathrm{~cm}$

2. Çift kişilik; $170 \mathrm{~cm} \times 200 \mathrm{~cm}, 190 \mathrm{~cm} \times 200 \mathrm{~cm}, 190 \mathrm{~cm} \times 220 \mathrm{~cm}$

3. Battal Boy; $200 \mathrm{~cm} \times 220 \mathrm{~cm}, 230 \mathrm{~cm} \times 250 \mathrm{~cm}$ 
4. Bebek yorganları; $70 \mathrm{~cm} \times 100 \mathrm{~cm}, 95 \mathrm{~cm} \times 145 \mathrm{~cm}$ olarak gruplandırılmaktadır.

Kılıf, yorganın tek ya da çift kişilik olmasına göre belirlenen ebatta, altı üstü patiska ya da altı patiska, desen uygulanacak kısmı deri saten gibi parlak kumaşlardan biçilmektedir. Kumaşların boyutları; patiska ve deri saten kumaş $220 \mathrm{~cm}$ enindedir. Genellikle kumaş toplarının boyu 40 metredir.

Biçilen kılıfın, alt en kısmı açık kalacak şekilde üç tarafı makinede dikilmektedir. Yorganın dikilmesi esnasında kumaş enden ve boydan $20 \mathrm{~cm}$ çekmektedir. Bu nedenle biçme işleminde kumaş gerçek ölçülerinden $20 \mathrm{~cm}$ daha uzun biçilmektedir.

Yorgan kılıfı dikildikten sonra kullanılacak iç malzemenin hazırlanmasına geçilmektedir. Kuzu yünü yıkanmış ve atılmış olarak atölyeye gelmektedir. Yorganı diktirmek isteyen kişi kullanılacak iç dolgu malzemesini ve kumaşı kendi getirdiği gibi, isterse yorgan ustasından bütün malzemeyi tedarik etmektedir. Yün dolgu malzemesi önce 1lık su ile yıkanıp kabartılmakta, hallaç makinesinde taranıp kullanıma hazır hale getirilmektedir. Pamuk dolgu malzemesi ise hallaç makinesinde taranıp kabartılmaktadır (Kartal, sözlü görüşme, 2019).

Yün dolgu malzemesi; 1 kişilik yorgan için 2-3 kilo, 2 kişilik yorgan için 3-4 kilo

Pamuk dolgu malzemesi; 1 kişilik yorgan için 2-3 kilo, 2 kişilik yorgan için 3-4 kilo

Yün-pamuk dolgu malzemesi; 1 kişilik yorgan için 1 kilo pamuk 2 kilo yün, 2 kişilik yorgan için 1 kilo pamuk 3 kilo yün

Boncuk elyaf dolgu malzemesi; 1 kişilik yorgan için 2 kilo, 2 kişilik yorgan için 3,5 kilo kullanılmaktadır.

İklim şartlarının zamanla değişmesi ve evlerin 1sıtma imkanlarının gelişmesinden dolayı önceden çift kişilik pamuk bir yorganın ağırlığı 7 kiloya kadar çıkarken günümüzde 3 kiloya kadar düşmüştür.

Kılıfi ve dolgu malzemesi hazırlanan yorgan dikiminin bir diğer aşaması dolgu malzemesinin kılıfa eşit şekilde yerleştirilmesidir. Kılıfin tersi yere serilmektedir. Altı, üstü patiska kılıfın hangi yüzünün üstte kalacağı önemli değildir. Bir yüzü patiska bir yüzü desenli olacak yorganın serilme işleminde hangi yüzün üstte kalacağı önemlidir. Patiska kumaş üstte, parlak, kayan kumaşlı yüz altta kalacak şekilde serilmelidir. Bunun nedeni, yorganın içine doldurulacak malzemenin döndürme esnasında kaymadan eşit şekilde iç kısma yerleştirilmesidir. Yere serilen kılıfın üstüne iç malzemesi serilir ve kapalı kısımdan rulo yapılarak en son kenarlardan kıvrılarak açık kısma gelindiğinde kılıf çevrilerek dolgu malzemesinin içeri girmesi sağlanmaktadır. Sırıkla dövülen dolgu malzemesi eşit şekilde dağıtılmaktadır. Bazı ustalar dolgu malzemesini kenarlara kalın, orta alana daha ince yerleştirmektedir. Bunun nedeni, kenardan başlatılan dikme işleminde dolgu malzemesinin yorganın ortasına doğru kaymasıdır. Desen uygulanacak yorgana motif, kalıp, tebeşir, sabun, kurşun kalem ya da çırpı ipi kullanılarak geçirilmektedir (Kartal, sözlü görüşme, 2019). (Şekil 12).

Şekil 12. Kurşun kalem ile baklava şişesi motifi çizilmiş yorgan ve dikilmiş hali, İsmet Kartal Atölyesi, Afyonkarahisar.

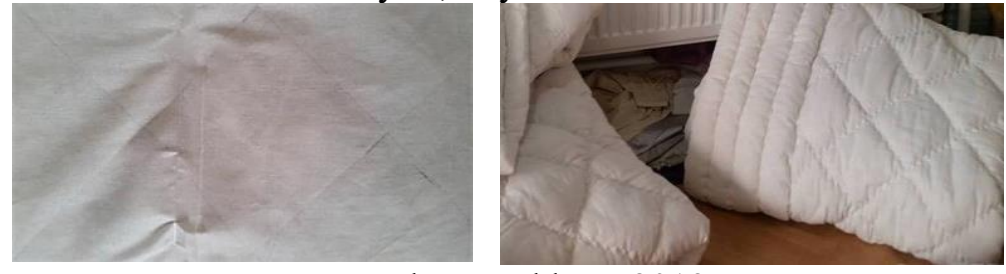

Kaynak: Küçükkurt, 2019 
Yorganın dikilmesi işlemine "Sırıma" denilmektedir. Türk dil kurumunun güncel Türkçe sözlüğünde sırıma; yorgan, şilte gibi eşyaların iri ve aralıklı, sağlam, sıkıca dikilmesi olarak tanımlanmaktadır (TDK, 2019).

Patiska yorganın dikimine kenarlardan başlanarak 4 sıra bordür oluşturulmaktadır. $\mathrm{Bu}$ yorganların orta kısmına baklava şişesi motifi yerleştirilmektedir. Dikme işleminde iplik gergin kullanılmamalıdır. İplik gergin kullanılırsa dolgu malzemesinin ağırlı̆̆ ipliğe baskı yaparak zamanla yorganın dikişlerinde kopmalar meydana getirecek, yorganda kabartılı görünüm ve istenilen yumuşaklık oluşmayacaktır. Yorgan üzerine uygulanacak desenin zorluğuna göre dikme süresi değişmektedir. Yorganların dikimi ve üzerine deseninin uygulama aşaması 2-3 gün arasında değişmektedir.

\subsubsection{Yorganların Renk, Desen ve Kompozisyon Özellikleri}

Yorganların renk, desen ve kompozisyon özellikleri alıcının isteğine göre şekillenmektedir. Zamanla yorgan dikiminde kullanılan malzemelerde, renk, desen ve kompozisyonlarda değişiklikler meydana gelmiştir. Renk tercihlerinde bu değişim açık bir şekilde görülmektedir. Eskiden fes rengi denilen bordo, mavi, sarı tercih edilirken günümüzde açık renkler, pastel tonlar tercih edilmektedir. Bu renkler arasında gümüş, krem, yavruağzı, pudra pembesi, lila, beyaz, yeşil, mavi bulunmaktadır.

Yorganların yüzüne uygulanan desenler zengindir. Bunlar bitkisel kökenli, geometrik, hayvan ve eşya konulu desenlerdir.

Bitkisel kökenli desenler; akasya çiçeği, papatya, serpme lale, buket lale, uzun menekşe, beş gül, söğüt dalı, hurma dalı, yonca yaprağı, bademli, gelincik çiçeği, kabak çiçeğidir.

Geometrik, hayvan ve eşya konulu desenler; tavus kuşu, midye kabuğu, çerçeveli, çavuş sırması, zincirli, göbekli, halı deseni, şemsiye, hasır örgü, pervane, parke, paket taşı, baklava, baklava şişesi, vabis desenidir.

Kompozisyonlarda desenler kaydırmalı olarak zemine yerleştirildiği gibi köşe göbek düzenlemeler de tercih edilmiştir. Aynı desenin tekrar ederek bütün zemini doldurulduğu yüzey düzenlemeleri mevcuttur.

Midye deseni, kumaşın desen özelliğine göre tasarlanmış bir modeldir. İşlemeli saten denilen kumaşın üzerinde bulunan kavislerin yorgan dikişi ile geçilmesiyle kompozisyon oluşturulmaktadır.

\subsection{Afyonkarahisar Yorganlarından Örnekler}

Afyonkarahisar'da evlerde kadın ustalar, atölyelerde erkek ustalar tarafindan dikilmiş geleneksel desenlere sahip yorganlar ailelerin yüklüklerinde, ustaların kataloglarda yer almaktadır. Bu bölümde, geleneksel değer taşıyan yorgan örnekleri malzeme, boyut, desen ve kompozisyon açısından incelenmiştir.

Şekil 13. Midye Kabuğu desenli pamuk yorgan, Afyonkarahisar.
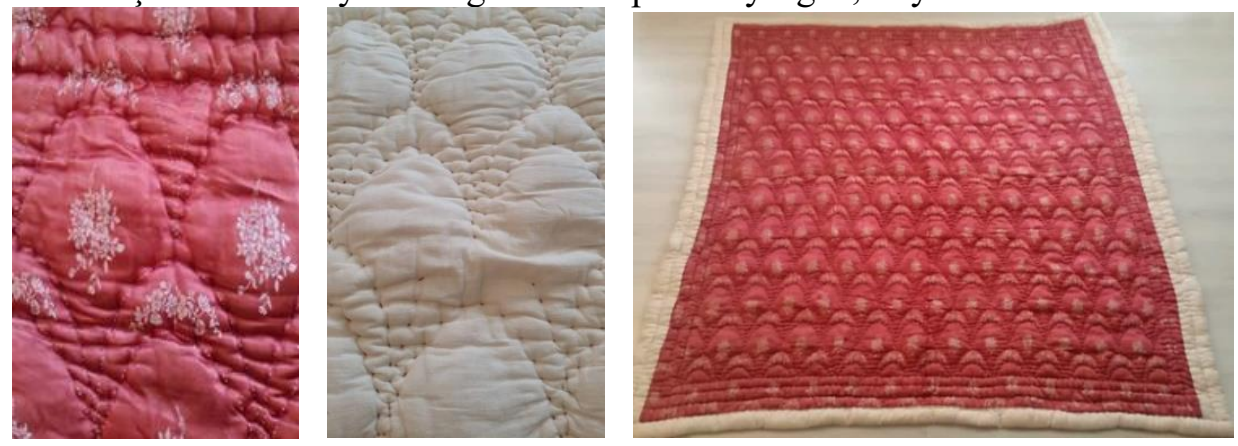

Kaynak: Küçükkurt, 2019 
Şekil 13'de yer alan örnek Leman Küçükkurt'un 1985 y1lında diktirdiği yorgandır. Astarı mermerşahi, yüzü işlemeli saten denilen kumaştan, $170 \mathrm{cmx} 200 \mathrm{~cm}$ boyutunda, pamuk dolgulu dikilmiştir. Kumaşın desenine uygun motif oluşturulmuştur. Şekli midyeye benzediği için "Midye Kabuğu” denilmiştir. Ağırlığ 6 kilo gelmektedir.

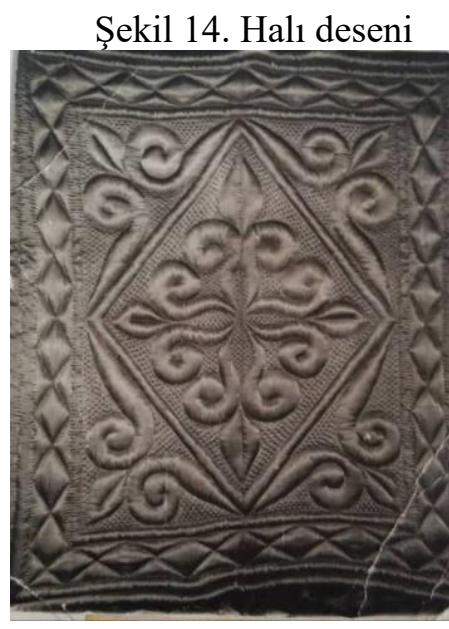

Kaynak: Kartal, 1990

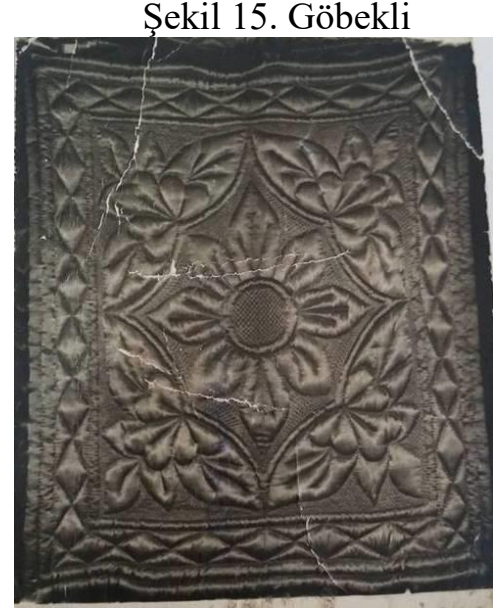

Kaynak: Kartal, 1990

Şekil 14 de "Halı Deseni", 15'de ise "Göbekli" kompozisyonuna sahip İsmet Kartal Usta'nın 1990 yılında diktiği, $190 \mathrm{~cm} x 200 \mathrm{~cm}$ ebadında çift kişilik yorganlar görülmektedir. Yorganların yüzü atlas, astarı mermerşahi kumaşından dikilmiştir. Usta, bu yorganları sahiplerine teslim etmeden önce fotoğraflarını çektirip desen kataloğuna eklemiştir.

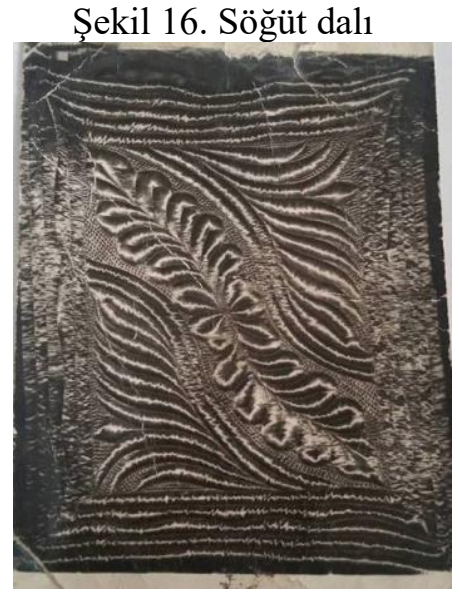

Kaynak: Kartal, 1980
Şekil 17. Hurma dalı

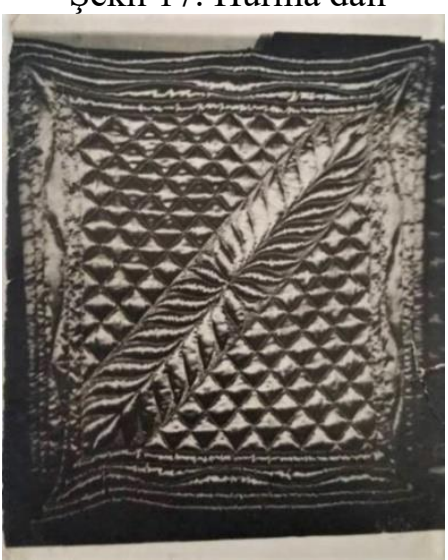

Kaynak: Kartal, 1983

Şekil 16 da "Söğüt Dalı", 17'de ise "Hurma Dalı" kompozisyonuna sahip İsmet Kartal Usta'nın diktiği 1980 ve 1983 yıllarına ait $190 \mathrm{~cm} x 200 \mathrm{~cm}$ ebadında çift kişilik yorganlar görülmektedir. Yorganın yüzü atlas, astarı mermerşahi kumaşından dikilmiştir. Bu yorganlar Kartal'ın desen kataloğunda bulunmaktadır. 
Şekil 18. Çerçeveli desenli yorganın yüzü ve arkası, Afyonkarahisar.
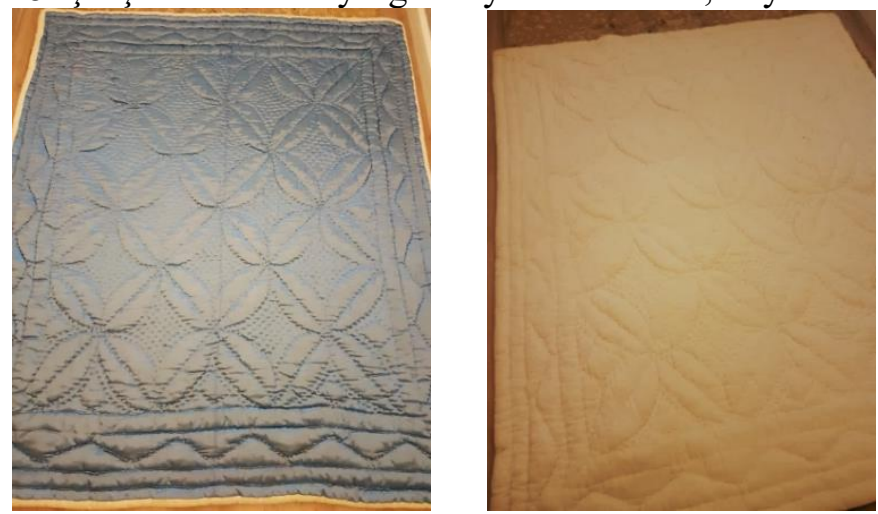

Kaynak: Yalçınkaya, 2019

Şekil 18'de yer alan örnek R. Gülenay Yalçınkaya'nın 1978 yılında diktirdiği yorgandır. Astarı patiska, yüzü saten kumaşından, $170 \mathrm{~cm} \times 200 \mathrm{~cm}$ boyutunda, pamuk dolgulu, "Çerçeve" desenli çift kişilik yorganın ağırlı̆̆ 5 kilo gelmektedir.

Şekil 19. Çavuş sırması yorganın yüzü ve arkası, Afyonkarahisar.
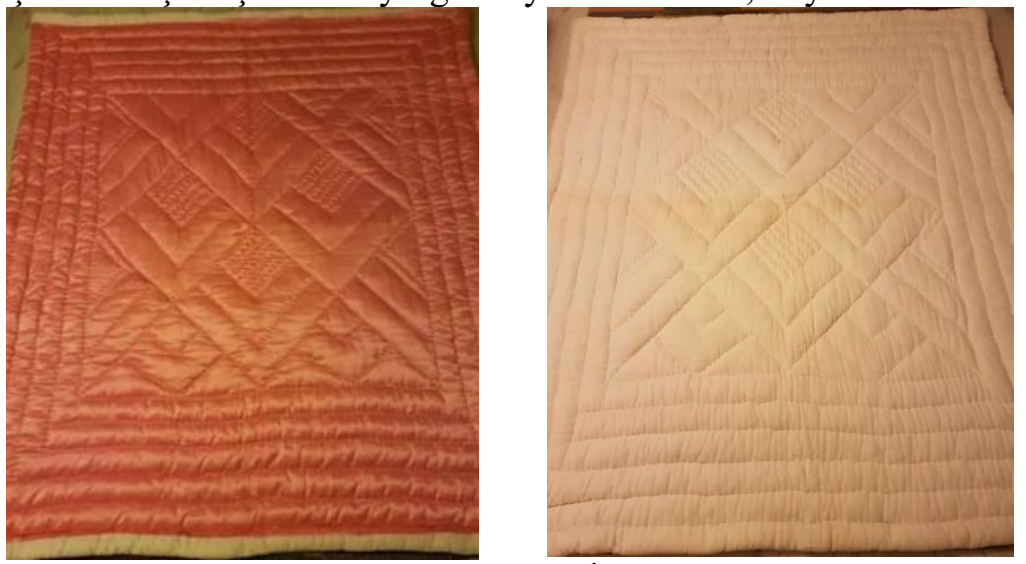

Kaynak: Yalçınkaya İlker, 2019

Şekil 19'de yer alan örnek Güneş Yalçınkaya İlker'e aittir. 2006 yılında dikilen yorganın astarı patiska, yüzü saten kumaşından $170 \mathrm{~cm} \times 200 \mathrm{~cm}$ boyutunda, pamuk dolgulu dikilmiştir. "Çavuş Sırması”" deseni uygulanmış yorganın ağırllğı 4 kilo gelmektedir.

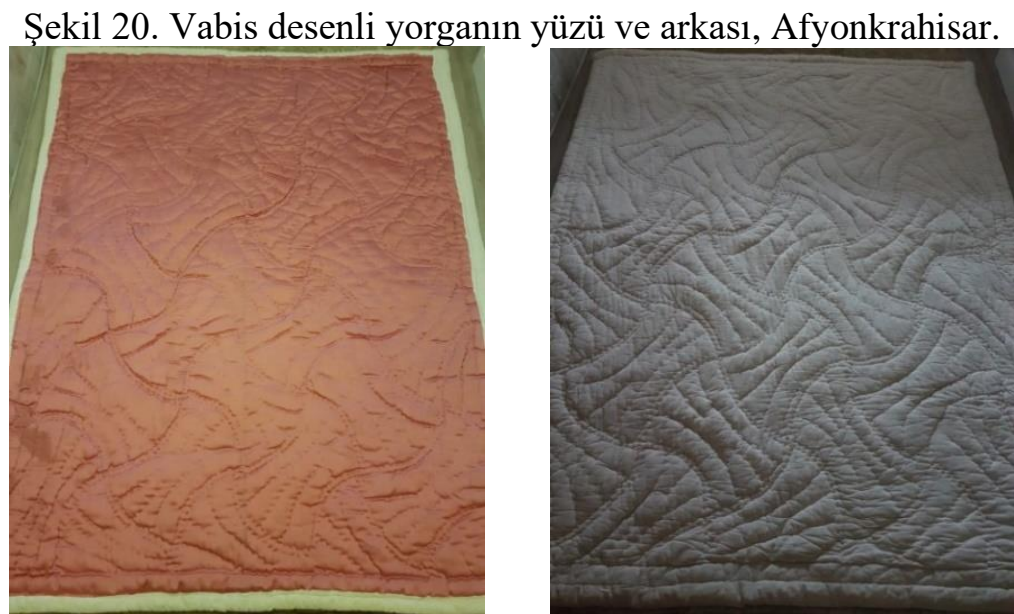

Kaynak: Yalçınkaya, 2019 
Şekil 20'de yer alan örnek R. Gülenay Yalçınkaya'ya aittir. 1978 yılında dikilen yorganın astarı patiska, yüzü saten kumaşından $170 \mathrm{~cm} x 200 \mathrm{~cm}$ boyutunda, pamuk dolgulu dikilmiştir. "Vabis" deseni uygulanmış yorganın ağırlığı 5 kilo gelmektedir.

Şekil 21. Baklava desenli yorganın yüzü ve arkası. Afyonkarahisar.

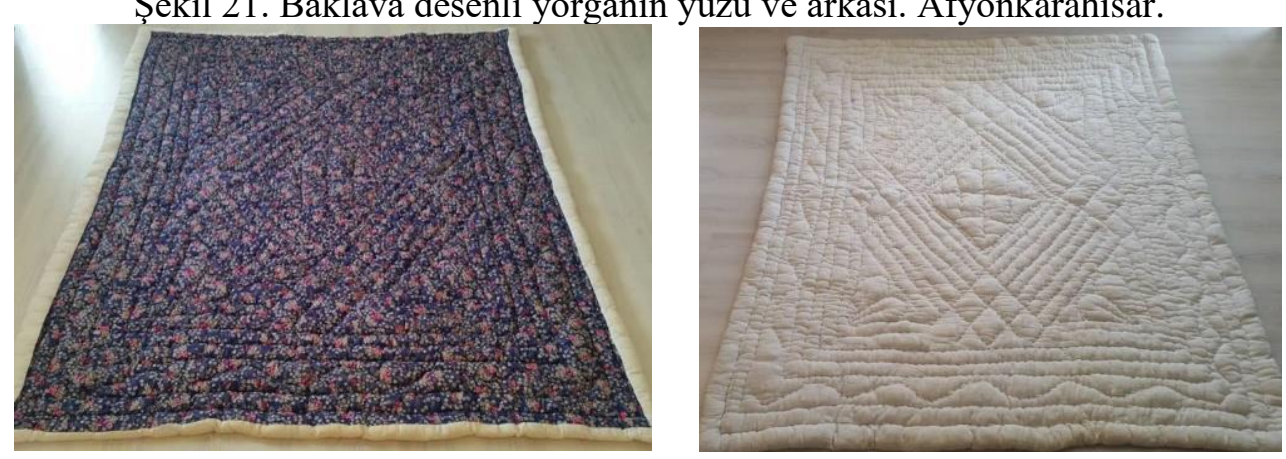

Kaynak: Küçükkurt, 2019

Şekil 21'de yer alan örnek Leman Küçükkurt'un 1980 yılında diktirdiği yorgandır. Astarı mermerşahi, yüzü basma kumaşından $170 \mathrm{~cm} \times 200 \mathrm{~cm}$ boyutunda, pamuk dolgulu dikilmiştir. "Baklava" desenine sahip yorganın ağırlığı 6 kilo gelmektedir.

Şekil 22. Solda "Kabak Çiçeği”, sağda "Göbekli” yorgan, İsmet Kartal Atölyesi, Afyonkarahisar.

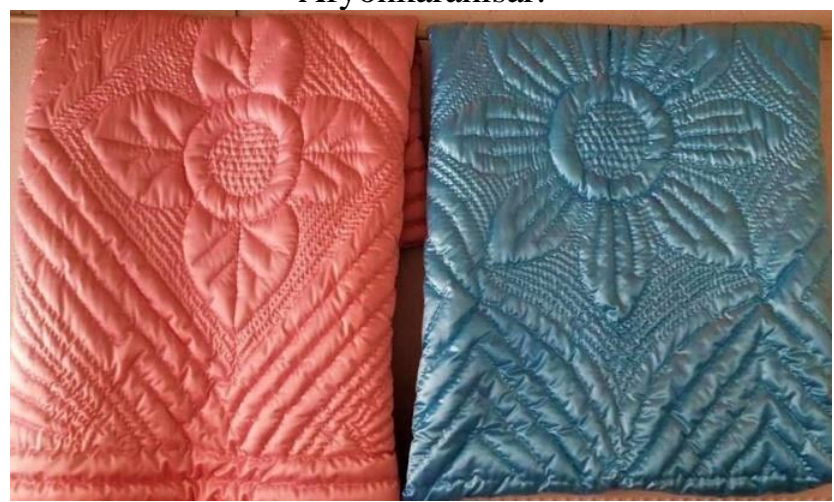

Kaynak: Küçükkurt, 2018

Şekil 22'de yer alan iki örnek İsmet Kartal Usta'nın, 2018'de diktiği yorganlardır. Astarı patiska, yüzü deri saten kumaşından $190 \mathrm{~cm} x 200 \mathrm{~cm}$ boyutunda pamuk-yün dolgulu dikilmiştir. Solda olan pembe yorgan "Kabak Çiçeği” sağda bulunan mavi yorgan "Göbekli" desenlidir. Yorganların ağırlığı 4 kilodur.

\section{Sonuç ve Öneriler}

Afyonkarahisar yaşamında önemli bir yere sahip olan yorganlar, ev eşyası ihtiyaç listesinin başında gelmektedir. Geleneksel yorgan üretiminde kullanılan malzemelerin doğal olması, sağlığ olumlu yönde etkilemektedir. Bu nedenle uzun yıllar kumaşlarda ve dolgu malzemelerinde pamuk, yün tercih edilmiş ancak son yıllarda bu malzemelerin üretiminin düşmesi, piyasa fiyatının artması gibi nedenlerle yorganların dikiminde kullanılan kumaş ve dolgu malzemelerinde değişim meydana gelmiştir. Bazı kumaş türlerinin üretiminin sona ermesi ya da pahalanması nedeniyle günümüz yorganlarında kullanılmamaktadır (Tablo 1,2). 
Tablo 1. Günümüzde üretilen yorganlarda kullanılmayan yüzlük ve astarlık kumaşlar.

\begin{tabular}{llll}
\hline Yüzlük & Basma kumaş & İşlemeli saten & Atlas \\
\hline Astarlık & Mermerşahi & & \\
\hline
\end{tabular}

Tablo 2. Günümüzde üretilen yorganlarda kullanılan yüzlük ve astarlık kumaşlar.

\begin{tabular}{llll}
\hline Yüzlük & Deri saten & İpek denim & Patiska \\
\hline Astarlık & Patiska & & \\
\hline
\end{tabular}

Yapılan bu araştırmada, eski Afyonkarahisar yorganlarının kumaşlarında koyu renklerin tercih edildiği, günümüzde ise pastel ve açık renklerin alıcılar tarafından istendiği görülmüştür. Eskiden, yorganların yüzüne daha yoğun ve zor desenler uygulanırken günümüzde daha sade desenler kullanılmaktadır (Tablo 3).

Tablo 3. Afyonkarahisar'da üretilen yorganların desen uygulama durumu.

\begin{tabular}{ll}
\hline Günümüzde uygulanmayan desenler & Günümüzde en çok uygulanan desenler \\
\hline Midye kabuğu & Baklava şişesi \\
\hline Halı deseni & Kabak çiçeği \\
\hline Hurma dalı & Papatya \\
\hline
\end{tabular}

Anadolu'nun birçok bölgesinde lale, tavus kuşu, çiçek motifleri yorgan yüzlerinde kullanılmış yörelerde farklı isim ve kompozisyonlarla karşımıza çıkmıştır. Örneğin, Afyonkarahisar bölgesinde görülen "Sögüt Dalı" kompozisyonu İzmir'in Tire ilçesinde yorgan yüzünde görülen "Sögüut Dalı" kompozisyonuyla, yine aynı bölgenin "Kilim" kompozisyonu Afyonkarahisar'ın yorgan yüzü "Halı Deseni" kompozisyonu ile benzer özellikler göstermektedir (Gümüşer, 2018: 234). Burdur bölgesinde görülen "Midye", "Karanfill", "Lale", "Paket Taşı" yorgan kompozisyonları (Çeliker ve Ölmez, 2012: 131), Torbalı'da uygulanan "Menekşe" deseni Afyonkarahisar yorganlarında görülmektedir (Çetin, 2013: 104). Ankara'da üretilen yorganlara uygulanan "Şemsiye" deseni Afyonkarahisar yorganlarında kullanılmıştır (Yardımc1, 2008: 109). Niğde'de görülen yorgan desenlerinden "Güneş", Afyon'da "Göbekli", Niğde'de görülen "Lale" kompozisyonu (Kemer ve Etikan, 2014: 32), Afyon'da "Serpme Lale" kompozisyonuyla benzerlik göstermektedir. $\mathrm{Bu}$ benzerlikler bölgelerde yapılan yorgan üretiminin bir birinden etkilendiğini göstermektedir. Desen ve kompozisyonlar benzer özellik gösterse de yöreler kendi estetik görüşleri doğrultusunda renk, desen ve kompozisyonlarda özgün örneklere sahiptir. Aynı isimle anılan kompozisyonlarda bile ustalar kenar suyu düzenlemesinde, göbek oluşturmada değişiklikler yapmış, bire bir uygulamadan kaçınmaya çalışmıştır.

Makine üretimi, boncuk, silikon elyaf gibi malzemelerle dikilmiş yorganların el dikimi pamuk, yün yorganlara göre daha ucuz ve hafif olması, el dikimi geleneksel yorgan ürünlerine talebi azaltmıştır. Ustaların yorgan üretiminden yeterli gelir elde edememesi, mesleklerini öğretecek çırak bulma ihtimallerini zayıflatmıştır. Yorgan üretiminin kaybolmaya yüz tutmasının nedenlerinden birisi de ürünlerin pazar bulamamasıdır. Pazar olanaklarının bu yönde geliştirilmesi gerekmektedir (Karatay ve Sert 2018: 102). Yorgan dikiminin yanı sıra üreticiler yer yatağı, tek yastık, çift kişilik yastık üreterek maddi yönden kazanç elde etmeye çalışmaktadır. Tüketicilerin doğal malzeme konusunda bilinçlendirilmesi, yeni pazarların araştırılması, üniversite halk işbirliği ile yorgan üretim projelerinin oluşturularak uygulanması gerekmektedir. Alınan bu tedbirler, Afyonkarahisar'da yorgan üretimini canlandırarak ustaların çırak yetiştirmesine imkân tanıyacak, mesleğin sürdürülebilirliğine destek verecektir.

\section{Kaynakça}

Çeliker, D. ve Ölmez, F. N. (2012). Burdur İlinde Yorganc1lık, Art-e, 5 (1): 122-138.

Çetin, N. (2013). Yorgan Kitabı, İçinde: Torbalı ve Civarında Yorgan Motifleri (Ed: E. G. Naskali), Ankara: Kitabevi. 
Duman, M. (2007). Geleneksel Türk Yorgancılık Sanatı, İstanbul: Heyamola Yayınları

Ercilasun, A. B. ve Akkoyunlu, Z. (2015). Kaşgarlı Mahmud Divanu Lugatit Türk, Ankara: Türk Dil Kurumu Yayınları.

Genç, R. (1997). Kaşgarlı Mahmud'a Göre XI. Yüzyılda Türk Dünyası, Ankara: Türk Kültürünü Araştırma Enstitüsü Yayınları.

Gümüşer, T. (2018). Kaybolmaya Yüz Tutmuş Geleneksel Türk Yorgancıllğının Analizi: Tire İlçesi Örneği, Akra Kültür Sanat ve Edebiyat Dergisi, 6 (15): 229-237.

Karatay, S. ve Sert, E. (2018). Aksaray El Sanatlarl, Ankara: Aksaray Valiliği Kültür ve Turizm Müdürlüğü Yayınları.

Kemer, G. ve Etikan, S. (2014). Niğde İli Kemerhisar Beldesinde Yorganc1lı,, Tarih Kültür ve Sanat Araştırmaları Dergisi, 3 (1): 25-36.

Ögel, B. (1991). Türk Kültür Tarihine Giriş 3. Cilt, Ankara: Kültür Bakanlığı Yayınları.

Öz, T. (1951). Türk Kumaş ve Kadifeleri 2. Cilt, İstanbul: Milli Eğitim Basımevi yayınları.

Türk Dil Kurumu (2019). Güncel Türkçe Sözlüğü,

http://www.tdk.gov.tr/index.php?option=com_gts\&arama=gts\&guid=TDK.GTS.5c55aad48259 c5.70231921 (Erişim Tarihi: 02.02.2019).

Yardımcı, N. (2008). Ankara El İşi Yorganları Üzerine Bir Araştırma, Gazi Üniversitesi Eğitim Bilimleri Enstitüsü Yüksek Lisans Tezi, Ankara.

\section{Kaynak Kişiler}

Darı, B. (2018). Yorgan Dikimi Konulu Görüşme.

Kartal, İ. (2018, 2019). Afyon Yorganc1lı̆̆1 Konulu Görüşme.

Küçükkurt, L. (2019). Afyon Yorganc1llğı Konulu Görüşme.

Uzun, İ. S. (2018). Afyonkarahisar Esnaf ve Sanatkârlar Odas1 Birliğine kayıtlı yorgan ustaları konulu görüşme.

Yalçınkaya, R. G. (2019). Afyonkarahisar Yorgancılığı Konulu Görüşme.

İlker, Yalçınkaya, G. (2019). Afyonkarahisar Yorgancılığı Konulu Görüşme. 